\title{
Proposta de prevenção de acidentes: um foco em aspectos comportamentais
}

\author{
Accident Prevention Proposal: a focus on behavioral aspects
}

Ana Paula da Silva ${ }^{\dagger}$, Enilson Salino Braga ${ }^{\dagger}$, Alex Franco Ferreira ${ }^{\dagger}$, José Thomaz de Carvalho ${ }^{\dagger}$

Como citar esse artigo. da Silva, AP; Braga ES; Ferreira AF; de Carvalho JT. Proposta de prevenção de acidentes: um foco em aspectos comportamentais. Revista Teccen. 2017 Ju1/Dez.; 10 (1): 03-09.

\begin{abstract}
Resumo
Diariamente, pessoas de diversas categorias e classes sociais sejam elas iniciantes, aprendizes ou até mesmo os mais experientes, estão envolvidas em algum tipo de acidente do trabalho, tendo como um dos influenciadores o fator humano. Este trabalho é uma revisão bibliográfica, onde através de pesquisas em revistas, artigos, dissertação de mestrado dentre outros recursos, buscou-se abordar o elevado número de acidentes do trabalho e apresentar propostas para prevenção dos mesmos, tendo como foco o aspecto comportamental. Verificou-se mais de 600 mil acidentes no ano de 2015, destes, mais de 2500 vieram a óbito, segundo dados da AEPS (2015). Partindo desse princípio, o presente trabalho fez uma abordagem em um dos fatores que propiciam o acidente do trabalho, que é o fator humano. A partir de então, buscou-se propostas para eliminar os acidentes, mas principalmente, trabalhar com medidas de prevenção que traga conscientização ao funcionário, para tanto foi apresentado o Programa 5S, a Auditoria Comportamental e a Ginástica Laboral. São medidas fáceis de implantar, podem ser desenvolvidas em qualquer empresa, porém para que as mesmas dêem resultados, deverá haver conscientização e transformação tanto por parte do empregado quanto por parte do empregador e principalmente deve haver comprometimento de ambas as partes. Conclui-se que essas medidas, embora sejam simples, podem trazer melhores condições de trabalho aos funcionários, bem como uma maior e melhor segurança, visto que todas elas visam uma melhor qualidade de vida no trabalho.

Palavras-Chave: Acidente do Trabalho; Aspecto Comportamental e Prevenção.
\end{abstract}

\begin{abstract}
Daily, people of diverse categories and social classes, be them beginners, apprentices or even the most experienced, are involved in some kind of work accident, having as one of the influencers the human factor. This work is a bibliographical review, where through researches in journals, articles, master's dissertation thesis among other resources, where looked for approach the high number of work accidents and present proposals for prevention of them, with focus on the behavioral aspect. There were more than 600 thousand accidents in the year 2015, of these, more than 2.500 died, according to data from AEPS (2015). Based on this principle, the present work made an approach in one of the factors that propitiate the work accident, which is the human factor. From then on, proposals were made to eliminate the acidentes, and mainly, work with prevention measures that would bring awareness to the employee, as for example: 5S Program, the Behavioral Audit and the Labor Gymnastics. It's easy to implement measures, that can be developed in any company, but for them to work, there must be awareness and transformation both on the part of the employee and on the part of the employer, and mainly there must be commitment of both part. It is concluded that these measures, while simple, can bring better working conditions for employees, as well as greater and better safety, since they all aim at a better quality of life at work.

Keywords: Accident at Work; Behavioral Aspect and Prevention.
\end{abstract}

\section{Introdução}

Diariamente, pessoas de diversas categorias e classes sociais sejam elas iniciantes, aprendizes ou até mesmo os mais experientes, estão envolvidas em algum tipo de acidente do trabalho, porém esses acontecimentos são minimamente divulgados pela mídia.

A Portaria 3.214/78 do Ministério do Trabalho e Empregos, aprova as Normas Regulamentadoras (NRs), relativas a segurança e medicina do trabalho, nelas são descritas as obrigações dos empregadores e empregados.

Para atender a grande demanda da sociedade contemporânea, a produção de bens e serviços tem aumentado demasiadamente, e muitas delas realizadas sem qualquer planejamento, acarretando riscos aos trabalhadores, população e ao meio ambiente.

Afiliação dos autores: † Universidade Severino Sombra - USS, Vassouras - RJ, Brasil.

* E-mail para correspondência: anapaulaengenheiraambiental@gmail.com 
Atualmente, tem-se um número exorbitante de acidentes do trabalho, tanto a nível mundial quanto nacional.

As razões para explicar o elevado número de ocorrências dos acidentes são as mais diversas, envolvendo falhas nos projetos dos sistemas de trabalho, dos equipamentos, das ferramentas, deficiência nos processos de manutenção dos diversos elementos componentes do trabalho. Ocupando lugar de destaque como causa dos acidentes de trabalho encontrase o fator humano, compreendendo características psicossociais do trabalhador, atitudes negativas para com as atividades prevencionistas, aspectos da personalidade, falta de atenção, entre outras (Dilascio, 2001).

Embora a culpa seja facilmente atribuída ao empregador, os trabalhadores também costumam apresentar resistências às mudanças. As pessoas tendem a agir dentro da empresa da mesma maneira que agem na sociedade. Fatores culturais, sociais e pessoais criaram nos brasileiros a cultura do desrespeito às regras (Spinelli, 2017).

Depende da atuação das empresas fazer com que os trabalhadores mudem seus comportamentos, para tanto a empresa deve orientá-los de forma clara, fiscaliza-los, supervisiona-los e se for necessário, puni-los.

Esse trabalho teve como objetivo demonstrar o alto índice de acidentes ocorridos no Brasil, com foco em umas das principais causas, o fator humano. Buscou-se abordar alguns comportamentos que propiciam os acidentes do trabalho, apresentando algumas medidas de prevenção.

A metodologia utilizada foi uma pesquisa exploratória, elaborada com base em publicações já realizadas tais como: revistas, artigos, dissertação de mestrado dentre outros recursos. Foi feito um levantamento do quantitativo de acidentes do trabalho ocorridos no Brasil, a partir de então, focou-se em um dos aspectos que propiciam o acidente, que é o aspecto comportamental. Para prevenir os acidentes, principalmente os acidentes ocasionados pelo fator humano, foram abordadas três formas de prevenção, são elas: Programa 5S, Auditoria Comportamental e Ginástica Laboral. Optou-se por abordar essas medidas, visto que as mesmas são fáceis de implantar e podem ser desenvolvidas em qualquer empresa, porém requer conscientização e transformação tanto por parte do empregado quanto por parte do empregador e principalmente deve haver comprometimento de ambas as partes.

\section{Acidente do trabalho}

Conforme dispõe o artigo 19 da Lei 8.213/91, Acidente do trabalho é o que ocorre pelo exercício do trabalho a serviço de empresa ou de empregador doméstico ou pelo exercício do trabalho, provocando lesão corporal ou perturbação funcional que cause a morte ou a perda ou redução, permanente ou temporária, da capacidade para o trabalho. Se classificam em 3 categorias: Acidente típico, acidente de trajeto e doença do trabalho.

De acordo como o Anuário Estatístico da Previdência Social - AEPS (2015), o Brasil ainda detém números elevados de acidentes de trabalho, conforme demonstrado na Tabela 1 .

Observa-se na Tabela 1, no ano de 2015, uma queda de $14 \%$ da taxa de acidentes do trabalho registrados no Brasil se comparado ao ano anterior, porém ainda é um número alarmante, provocando não só danos graves aos trabalhadores, mas também perdas sociais para as organizações bem como enormes encargos sociais a Nação.

Ainda de acordo com o AEPS (2015), foram registrados no Brasil no ano de 2015, 2.502 óbitos, isso significa uma média de mais de 6 óbitos diários. O Gráfico 1, demonstra esse quantitativo na forma percentual e distribuídos conforme as regiões do Brasil.

Tabela 1. Quantidade de acidentes do trabalho ocorridos no Brasil.

\begin{tabular}{|c|c|c|c|c|c|c|}
\hline \multirow{4}{*}{ Anos } & \multicolumn{6}{|c|}{ QUANTIDADE DE ACIDENTES DO TRABALHO } \\
\hline & \multirow{3}{*}{ Total } & \multicolumn{4}{|c|}{ Com CAT Registrada } & \multirow{3}{*}{$\begin{array}{c}\text { Sem CAT } \\
\text { Registrada }\end{array}$} \\
\hline & & \multirow[b]{2}{*}{ Total } & \multicolumn{3}{|c|}{ Motivo } & \\
\hline & & & Tipico & Trajeto & $\begin{array}{c}\text { Doença do } \\
\text { Trabalho }\end{array}$ & \\
\hline 2013 & 725.664 & 563.704 & 434.339 & 112.183 & 17.182 & 161.960 \\
\hline 2014 & 712.302 & 564.283 & 430.454 & 116.230 & 17.599 & 148.019 \\
\hline 2015 & 612.632 & 502.942 & 383.663 & 106.039 & 13.240 & 109.690 \\
\hline
\end{tabular}




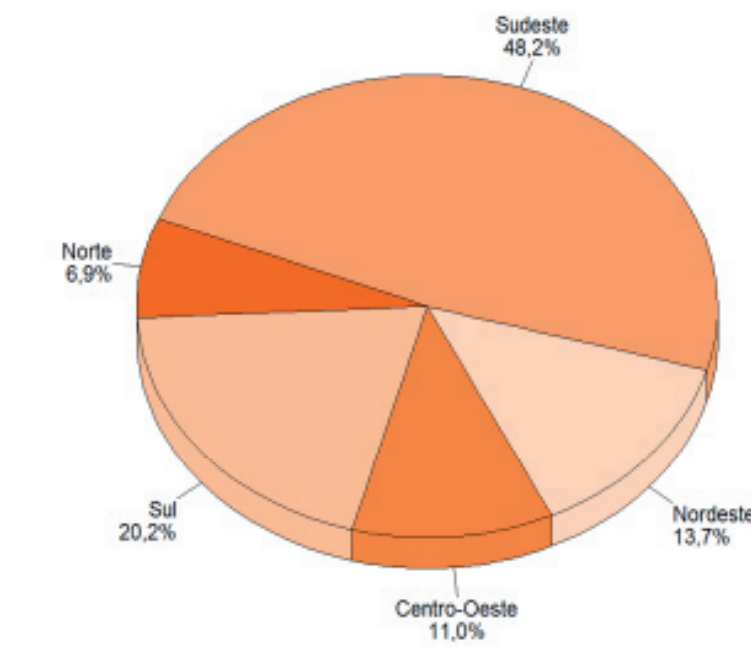

Gráfico 1. Distribuição dos óbitos nas grandes regiões do Brasil no ano de 2015. Fonte Anuário Estatístico da Previdência Social (2015).

Percebe-se que a região sudeste detém quase $50 \%$ dos óbitos, isso se explica devido ao fato da região ser a mais populosa do país e deter o maior parque industrial.

A melhor forma de se evitar essa quantidade enorme de acidentes, ainda é através da prevenção. Prevenir ainda é a melhor maneira de evitar que um acidente aconteça, por isso é preciso criar uma mentalidade preventiva tanto nos empregados como nos empregadores, buscando sempre evitar os improvisos e promovendo conscientização em relação aos riscos no ambiente de trabalho, treinando e educando os funcionários para a utilização dos equipamentos adequados para a função exercida (Miranda, 2009).

\section{Aspectos comportamentais}

Pensando na concepção do modelo de causa e efeito do acidente, o fator humano é retratado pela interação da ação realizada, ou não pelas pessoas no decorrer das suas atividades do trabalho, sendo o resultado do seu comportamento de segurança na execução das suas atribuições (Bozzetto, 2012).

Um ambiente de trabalho pode melhorar o relacionamento interpessoal, reduzir acidentes, doenças, faltas consecutivas e até mesmo a rotatividade do quadro de funcionários, ao terem essa percepção, as organizações passaram a perceber o quanto a saúde do seu colaborador é importantes para a sustentabilidade empresarial (Alcântara, 2014).

Para Zocchio (2002), as falhas do ser humano podem ser descritas como fatores hereditários, sociais e de educação. Entretanto podem-seconsiderar condições de saúde, estado de ânimo e temperamentos, que em determinadas circunstâncias podem proporcionar condições para a ocorrência do acidente.

De acordo com Zocchio (2002), alguns comportamentos ou aspectos explicam o porquê, ou o que propiciou o acidente do trabalho:

Inaptidão para o trabalho devido as dificuldade de aprendizagem, aspectos de conhecimento para o desempenho da atividade ou sem a possibilidade de adequação na execução da tarefa;

Temperamento: alteração repentina de humor, sentimento de sentir-se mais ou menos seguro na atividade que exerce, de pessoas que não aceitam ordens, pessoas irritadiças entre outros;

Stress: O stress consiste em um conjunto de perturbações que caracterizam o desequilíbrio físico e psíquico, segundo indicadores, em 2020, os transtornos mentais devem ser a principal causa de afastamentos;

Motivação imprópria: é a percepção da pessoa que desconhece a importância do seu trabalho, ou possui baixo grau de orgulho no desempenho da atividade.

Além desses aspectos, pode-se acrescentar a qualidade de vida no trabalho, pois o homem passa maior parte de sua vida em seus locais de trabalho, dedicando sua força, energia e esforços para as organizações. Ou seja, disponibilizando maior parte do seu tempo ao trabalho do que propriamente com suas famílias e amigos. O nível de pressão por resultados, 
a concorrência e a complexidade por um espaço no mercado, fazem com que o trabalho seja uma constante na vida do homem moderno (Cavassani, 2006).

O comportamento humano tem exercido influência direta no desempenho das organizações e, portanto, seu estudo associado a prevenção e controle das perdas torna-se relevante para obtenção do grau de excelência em sua gestão de SMS (Segurança, Meio Ambiente e Saúde), ou seja, a melhoria das condições de segurança e do ambiente traz incrementos na qualidade de vida dos empregados, das comunidades que possam ser afetadas e consequentemente, ganhos para a empresa.

\section{Prevenção de acidentes focada em aspectos comportamentais}

Buscando eliminar os acidentes, muitas empresas estão investindo na segurança do trabalho, objetivando eliminar condições abaixo do padrão, mas principalmente conscientizar seus funcionários a fim de se evitar atos abaixo do padrão. Para tanto existem algumas medidas de prevenção.

\section{Programa 5S}

Um dos métodos mais adotados é o chamado $5 \mathrm{~S}$, este é considerado a base para a segurança comportamental. Tal denominação provém de cinco atividades que fazem parte da metodologia criada no Japão no final da década de 1950, conforme demonstrado na figura 1 (Ribeiro, 2017).

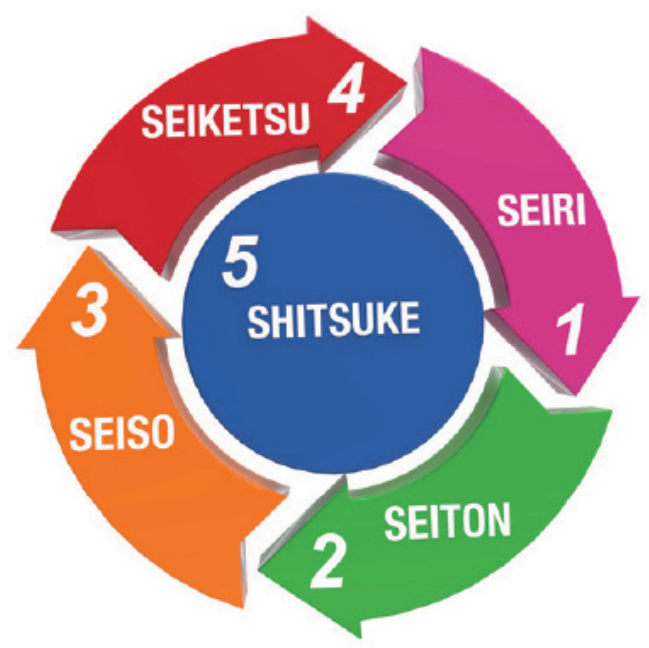

Figura 1. Metodologia 5S. Fonte: Revista CIPA, 2017.
Segundo Silva et al. (2001), o Programa 5Ss tem como objetivo básico a melhoria do ambiente de trabalho, nos sentidos físico (layout da organização) e mental (mudança de paradigmas das pessoas). O programa visa otimizar espaços, melhorar o ambiente e evitar desperdícios. Além disso, auxilia na parte psicológica das pessoas, as quais se tornam mais comprometidas com o processo e com a empresa, deixando de lado velhos paradigmas.

O Programa 5S é composto por 5 passos, e cada um tem um significado dentro do programa, conforme descrito a seguir:

Seiri - utilização, seleção e classificação: preza pela utilização adequada dos recursos e instalações, evitando desperdícios. Além disso, critica improvisações e problemas de conservação que gerem riscos.

Seiton - organização, ordenação e arrumação: é saber utilizar os recursos sem desperdiçar e de forma organizada, tornando o ambiente seguro e produtivo.

Seiso - limpeza do ambiente e instalações: busca a eliminação de sujeiras, gerando assim um ambiente mais seguro, que facilita na detecção de futuras anormalidades, incluindo condições inseguras.

Seiketsu - padronização, saúde e higiene: se trata, basicamente de padronizar todos os procedimentos, hábitos e normas, de modo que sejam mantidos os três primeiros "Ss" anteriores, mantendo a higiene e a limpeza.

Shitsuke - autodisciplina: exige para seu cumprimento a autodisciplina, os procedimentos de trabalho e normas de segurança, devem ser cumpridos voluntariamente pelos funcionários.

O programa $5 \mathrm{~S}$ pode ser implantado em qualquer empresa, para tanto deverá ser montado grupos de promoção para divulgar o programa, realização de palestras de conscientização e envolvimento dos funcionários, capacitando-os para a realização dos sensos. Preferencialmente um responsável da diretoria deve participar deste grupo, a fim de demonstrar comprometimento da alta direção aos demais colaboradores (Gavioli, 2009).

\section{Auditoria Comportamental}

Auditoria Comportamental consiste basicamente 
na abordagem de indivíduo, funcionário, observar, dirigir a uma única pessoa e ou a um grupo de pessoas de modo que a se notar ou identificar certo aspecto não comum ou inadequado, seja realizado uma intervenção do observador para que haja uma interrupção na sequencia daquele determinado evento e ou trabalho que está sendo realizado dentro de qualquer organização e ou empresa e indiferente do tipo de grau de risco e quantidade de funcionários (Simioni, 2015).

Para melhor observância, esta ferramenta considera seis categorias, são elas:

Reação das pessoas - observa-se como o funcionário e/ou grupo em questão reage quando o auditor entra em uma área, observa-se se eles estão re-arrumando o trabalho; parando de trabalhar completamente; ou colocando seus EPIs; dentre outros. Segundo Meneghetti (2010), esse tipo de reação, mostra que o trabalhador sabe o que é certo, mas não o faz, sugerindo assim que o trabalhador não acredita ou não dá o devido valor aos procedimentos de segurança;

Posição das Pessoas - Analisa-se a postura de como o trabalhador realiza suas atividades durante a jornada, toma-se como base o ambiente de trabalho, máquinas e dispositivos estão adequados a sua estrutura. Como por exemplo, observa-se se alguém está fadigado ou estressado; se alguém pode estar em contato com contaminantes entre outros;

EPI (Equipamento de Proteção Individual) observa-se não somente o uso, mas se o mesmo está sendo utilizado de forma correta; se o mesmo está em boas condições de uso e higiene; se o EPI é adequado para determinada função, entre outros;

Ferramentas e equipamentos - observa-se se as ferramentas são apropriadas para a função; se estão em excelentes condições de uso; entre outros;

Procedimentos - observa-se se os procedimentos são adequados para efetuar tal serviço; se o trabalhador tem conhecimento do procedimento requerido; se o trabalhador esta seguindo o procedimento, entre outros;

Ordem, limpeza e arrumação - observase se o ambiente está livre de sujeira, pó, contaminantes; se está organizado. Quanto mais limpo e organizado estiver o ambiente de trabalho, melhor será a qualidade e a segurança no trabalho, consequentemente o trabalhador terá uma sensação de bem estar.

Auditoria comportamental é uma ferramenta de gestão que não se propõe a apenas identificar os desvios, mas também trata-los e contribuir para o desenvolvimento da cultura de segurança (Meneghetti, 2010).

\section{Ginástica laboral}

A ginástica laboral compreende práticas de exercícios específicos de alongamento, fortalecimento muscular, coordenação motora, tendo como prevenção e diminuição de casos de LER (Lesão por Esforço Repetitivo/DORT - Distúrbios Osteomusculares Relacionados ao Trabalho), tem como objetivo promover a consciência corporal; reduzir a fadiga muscular; a saúde e o bem estar; promover a integração entre os funcionários; reduzir os números de acidentes de trabalho; aumentar a motivação no trabalho e prevenir as doenças ocupacionais (Alcântara, 2014).

Para obter bons resultados com a implantação da ginástica laboral dentro de uma empresa, a mesma deverá zelar para que os exercícios sejam bem planejados, estruturados e específicos para cada posição de ocupação. É uma ginástica que favorece a atenção e a autoestima, além de trabalhar o corpo, e estimulando o autoconhecimento, proporcionando um ótimo relacionamento em equipe com o meio e trazendo mudanças dentro e fora do trabalho (Lima, 2004).

A ginástica laboral classifica-se, de acordo com o momento em que é aplicada dentro da empresa, conforme descrito a seguir:

Ginástica Laboral Preparatória - atividade física realizada antes de se iniciar o trabalho, aquecendo e despertando o funcionário, com objetivo de prevenir acidentes de trabalho, distensões musculares e doenças ocupacionais (Dias, 1994);

Ginástica Laboral Compensatória - como o nome já diz, esse tipo de exercício tem o objetivo de fazer uma compensação dos músculos, pois trabalha e relaxa os músculos que estão sendo utilizados ou contraídos, respectivamente, durante a jornada de trabalho;

Ginástica Laboral Relaxante - praticada ao final do expediente, tem como objetivo extravasar tensões, proporcionando relaxamento muscular e mental aos trabalhadores (Oliveira, 2006); 
Ginástica Laboral Corretiva - A aplicabilidade dessa ginástica tem como objetivo trabalhar grupos específicos dentro da empresa, em conjunto com a área da medicina do trabalho, da enfermagem e da fisioterapia, com a finalidade de recuperar casos graves de lesões, de limitações e de condições ergonômicas (Sampaio, 2008).

Segundo Lopes (2008), funcionários que praticam a Ginástica Laboral estão se beneficiando fisiologicamente, pois diminui as doenças ocupacionais no trabalho; diminui as dores musculares, inflamação e trauma; o funcionário estará mais preparado no serviço, sem precisar sentir desconforto e melhora a postura corporal. A Ginástica laboral trás benefícios também no aspecto psicológico, visto que refletem na elevação da autoestima e diminui a ansiedade, buscando um melhor equilíbrio dentro da empresa. Benefícios sociais também são consequências da ginástica laboral, pois proporciona mudanças no estilo de vida; aumentará o trabalho em equipe, promovendo uma melhor integração entre todos os funcionários. Além dos benefícios citados, a ginástica laboral também contribui para a empresa lograr um bom desenvolvimento e produtividade, visto que terão diminuição de atestados médicos; diminuição das doenças de lesões musculares, dores e tensões ocasionadas pelos esforços repetitivos; aumento de capacidade em movimentos, diminuindo as falhas, os erros que acontecem quando estão com problemas na saúde (Ferreira, 2013).

A implantação de um programa de ginástica laboral busca despertar nos trabalhadores a necessidade de mudanças do estilo de vida e não apenas de alteração nos momentos de ginástica orientada dentro da empresa.

\section{Considerações Finais}

Com base no conteúdo desenvolvido neste trabalho, percebeu-se que a situação atual do trabalhador brasileiro em relação à saúde e segurança do trabalho, é insatisfatória, visto que ainda são acometidos no Brasil um alto índice de acidentes, muitos destes convergindo para o óbito, incapacidade permanente ou ainda acarretar em um grande período de afastamento desse funcionário.

As medidas abordadas, foram escolhidas devido ao fato de serem fáceis de implantar, podem ser desenvolvidas em qualquer empresa e principalmente não requer gastos, porém para que as mesmas sejam funcionais, deve haver conscientização e transformação tanto por parte do empregado quanto por parte do empregador e principalmente deve haver comprometimento de ambas as partes.
Conclui-se que essas medidas, embora sejam simples, podem trazer melhores condições de trabalho aos funcionários, bem como uma maior e melhor segurança, visto que todas elas visam uma melhor qualidade de vida no trabalho, mas principalmente, enfocam a conscientização, portanto funcionários que possuem boa informação, capacitação e principalmente adquirem consciência de que seus comportamentos podem determinar o quanto vale sua vida, não vai colocá-la em risco e estes certamente serão funcionários mais saudáveis, produtivos e mais felizes, consequentemente isso acarretará grandes benefícios para a empresa.

\section{Referências bibliográficas}

Alcântara, D. L. de F., et al. (2014). Busca por uma melhor qualidade de vida no trabalho utilizando a ginástica labora como ferramenta - artigo apresentado no XI Simpósio de Excelência em Gestão e Tecnologia.

Bozzetto, M. (2012). Fatores pessoais que interferem no acidente de trabalho - artigo apresentado no XXXII Encontro Nacional de engenharia de Produção.

Brasil. (2015). Anuário Estatístico da Previdência Social. Disponível em: http:/www.previdencia.gov.br/wp-content/uploads/2015/08/AEPS-2015FINAL.pdf - acessado em 02/05/2017.

Cavassani, A. P., Cavassani, E. B., \& Biazin, C. C. (2006). Qualidade de vida no trabalho: fatores que influenciam as organizações - artigo apresentado ao XIII SIMPEP.

Di Lascio, C. H. R. (2001). A Psicologia no trabalho. Revista Contato - CRP 08, ano 23, $\mathrm{n}^{\mathrm{o}}$. 113, Curitiba, p.11.

Ferreira, K. S., \& Santos, A. P. (2013). Os Benefícios Da Ginástica laboral e os possíveis motivos da não implantação - artigo apresentado a Revista Educação Física UNIFAFIBE, Ano II, n. 2, p. 56-72.

Gavioli, G, Siqueira, M. C. M., \& Silva, P. H. R. (2009). Aplicação do Programa $5 \mathrm{~s}$ em um sistema de gestão de estoques de uma indústria de eletrodomésticos e seus impactos na racionalização de recursos - artigo apresentado ao SIMPOI.

Lei $\mathrm{n}^{\circ}$ 8.213, de 24 de julho de 1991. Dispõe sobre os Planos de Benefícios da Previdência Social e dá outras providências. Brasília, DF.

Lopes, T. C. E., Nogueira, E. J,., \& Martinez, M. R. L. (2008). Influencia da ginástica laboral em funcionários que trabalham com telemarketing.. Disponível em: http://www.efdeportes.com/efd124/ginastica-laboral-emfuncionarios-que-trabalham-com-telemarketing.htm . Acessado em 02 de junho de 2017.

Meneghetti, A. A. (2010). A importância da auditoria comportamental para a prevenção de acidentes na indústria petroquímica - Dissertação apresentada a Curso de Mestrado em Sistemas de Gestão da Universidade Federal Fluminense, Niterói, Rio de Janeiro.

Miranda, K. F. (2009). Acidentes de trabalho: principais causas e prevenções - artigo apresentado no XIII Encontro Latino Americano de Iniciação Científica e IX Encontro Latino Americano de Pós-Graduação.

Oliveira, J. R. G. (2006). A prática da ginástica laboral. 3. ed. Rio de Janeiro: Sprint.

Ribeiro, H. (2017). Cinco etapas preventivas - artigo revista CIPA, edição março de 2017.

Sampaio, A. A., \& Oliveira, J. R. G. (2008). A Ginástica Laboral na promoção da saúde e melhoria da qualidade de vida no trabalho. Caderno de Educação Física, Marechal Cândido Rondon. 7(13): 2.

Simioni, A. F., \& Patrocínio, A. B. (2015). Segurança Comportamental em ambientes de trabalhos - artigo apresentado ao curso de especialização em engenharia de segurança do trabalho na FATEP. 
Simioni, A. F., \& Patrocínio, A. B. (2015). Segurança Comportamental em ambientes de trabalhos - artigo apresentado ao curso de especialização em engenharia de segurança do trabalho na FATEP. Um programa passageiro ou permanente? XXI ENEGEP, 2001.

Spinelli, L. E. (2017). Compromisso de todos - artigo Revista CIPA. 